\title{
INFÂNCIA, EDUCAÇÃO E RELAÇÕES ÉTNICO-RACIAIS: A PRODUÇÃO ACADÊMICA NOS ÚLTIMOS ANOS
}

\author{
Erika Jennifer Honório Pereira ${ }^{1}$ \\ Aretusa Santos Rosa ${ }^{2}$ \\ Vera Maria Ramos de Vasconcellos ${ }^{3}$
}

\section{INTRODUÇÃO}

Infância, Educação e relações étnico-raciais são áreas com histórico de invisibilidade e silenciamento. Vasconcellos e Sarmento (2007, p. 33) afirmam que: "A busca de um conhecimento que se desgarre das imagens constituídas e, historicamente, sedimentadas não pode deixar de ser operada senão a partir de um trabalho de desconstrução dos seus fundamentos".

Ambas as áreas apresentam um quadro de produções emergentes nos últimos anos, contudo as interfaces infância e relações étnico-raciais ainda apresentam um número mais reduzido de publicações. "As pesquisas vêm estudando, principalmente, processos de exclusão de crianças negras no âmbito da educação a partir do ensino fundamental. As pesquisas relacionadas à educação infantil são raras e recentes, e, mesmo assim, se circunscrevem à pré-escola e ao pré-escolar." (ROSEMBERG, 2012, p.12).

Nesta perspectiva, o artigo discute dez anos de publicações de teses e dissertações e as comunicações orais das Reuniões Anuais da Associação Nacional de Pesquisadores em Educação - ANPED produzidas no Brasil, considerando o período de 2003 a 2013 na interface em discussão. Correspondem a dados desenvolvidos pela primeira autora, na dissertação de mestrado (PEREIRA, 2015) e da segunda nas análises de doutorado (ROSA, 2016) trabalhos estes orientados pela terceira autora.

O levantamento possibilita-nos refletir sobre a produção acadêmica no campo das relações étnico-raciais com ênfase na infância, mais especificamente, na

\footnotetext{
${ }^{1}$ Mestre em Educação pelo Programa de Pós-graduação em Educação da Universidade Estadual do Rio de Janeiro- PROPED/UERJ, vinculada ao Núcleo de Estudos em Infância: Pesquisa e Extensão NEI:P\&E/UERJ, erikajen_@hotmail.com

${ }^{2}$ Doutoranda do PROPED/UERJ, vinculada ao NEI:P\&E/UERJ, aretusasantos@yahoo.com.br.

3 Coordenadora do Núcleo de Estudos da Infância e Juventude: Pesquisa \& Extensão NEI:P\&E/UERJ. Professora Titular do Departamento de Estudos da Infância/UERJ e do Programa de Pós-graduação em Educação/UERJ. vasconcellos.vera@gmail.com
} 
Educação Infantil, possibilitando mapear áreas em expansão e/ou lacunas existentes.

O recorte temporal "2003-2013" que orientou a investigação foi a promulgação e a implantação da Lei no $10.639 / 03^{4}$, que modificou a Lei de Diretrizes e Bases da Educação Nacional- LDB n 9.394/06, com a inclusão dos artigos 26a e 79b. A Lei foi, sem dúvida, um marco significativo das conquistas daqueles que anseiam por uma educação antirracista.

Embora tenha tornado obrigatório o ensino de cultura e história afrobrasileira apenas aos estabelecimentos de Ensino Fundamental e Médio, oficiais e particulares, em 2004, o Conselho Nacional de Educação (CNE) elaborou o Parecer 03/2004 e, posteriormente, a Resolução 1/2004, que instituiu as Diretrizes Curriculares Nacionais para a Educação das Relações Étnico-Raciais e para o Ensino de Historia e Cultura Afro-Brasileira e Africana - DCNERER, que enfatizou a obrigatoriedade da inclusão das discussões étnico-raciais nos currículos da Educação básica, incluindo, por conseguinte, a educação infantil.

A pesquisa foi realizada em duas etapas. Inicialmente, analisamos teses e dissertações brasileiras sobre educação, relações étnico-raciais e infância Posteriormente, realizamos o levantamento das Comunicações Orais apresentadas na Associação Nacional de Pesquisadores em Educação - ANPED.

\section{TESES E DISSERTAÇÕES}

A análise das teses e dissertações produzidas nos programas de pósgraduação de todo o território nacional se deu a partir das seguintes bases de dados eletrônicas: portais da Biblioteca Digital Brasileira de Teses e Dissertações (BDTD), Instituto Brasileiro de Ciência e Tecnologia (IBICT), Banco de Teses da Coordenação de Aperfeiçoamento de Pessoal de Nível Superior (CAPES), Domínio Público e Google.

Utilizamos os seguintes descritores: raça, racismo, discriminação (racial), preconceito (racial), relação(ões) étnico-racial(is), etnia, negro(a); negritude(a); branco(a); preto(a); multicultural, diversidade, multiculturalismo, afro-brasileiro(a); afrodescendente, Educação Infantil; pré-escola; creche; infância, criança. 0

\footnotetext{
${ }^{4}$ Alterada pela Lei no 11.645 , de 2008, Lei oㅜ 11.645/08, que acrescentou a obrigatoriedade do ensino da História e Cultura Indígena.
} 
quantitativo de descritores denota a variedade de expressões utilizadas referentes ao tema. Apesar do seu grande número, o resultado do levantamento de teses e dissertações encontradas foi baixo.

Outro critério de seleção na busca por teses e dissertações foi a restrição a trabalhos que refletiam sobre a faixa etária de 0 a 6 anos, critério que restringiu mais ainda as pesquisas encontradas, pois muitas relacionadas à criança, à infância e à Educação Infantil traziam também dados relativos a outras faixas etárias.

Ao final do período de busca nos portais foram encontradas 03 teses (DIAS, 2007; MONTEIRO, 2010; TRINIDAD, 2011) e 23 dissertações (OLIVEIRA, 2004; SANTOS, 2005; OLIVEIRA, 2006; SILVA, C. 2007; CABRAL, 2007; ROCHA, 2008; SANTOS, 2008; SARAIVA, 2009; SOUZA Y., 2009; OLIVEIRA, 2009; SOUZA F., 2009; DERMARZO, 2009; MOTTA, 2010; TELES, 2010; QUEIROZ, 2011; OLIVEIRA, 2011; NUNES, 2012; SOUZA, 2012; OLIVEIRA, 2012; CARVALHO, 2013; COSTA, 2013; BISCHOFF, 2013 e GAUDIO, 2013).

Tal panorama da produção acadêmica brasileira na interface em estudo 23 dissertações e 23 teses - apontou-nos que a discussão concentra-se na produção de pesquisadores iniciantes.

Indagamos, o que isso significa? Este é um tema novo, por isso 23 dissertações? Por que a maioria dos pesquisadores que investiram no tema no mestrado não o seguiram no doutorado? Registramos a necessidade de mais discussões e pesquisas sobre o tema na pós-graduação brasileira.

A partir das teses e dissertações encontradas obtivemos informações sobre a distribuição das produções acadêmicas, por ano de defesa, Universidade à qual se vinculam, região em que se localizam e tema investigado.

Com relação ao ano de defesa das teses, chama atenção o reduzido número das que vinculam infância e raça. Na última década, encontramos apenas três, defendidas em 2007, 2010 e 2011, apenas uma a cada ano.

É possível perceber na distribuição das dissertações por ano de defesa no período investigado, que houve um acréscimo no número de dissertações, em comparação aos anos iniciais. Em 2003 não houve nenhuma dissertação encontrada. Em 2004, 2005 e 2006, uma dissertação a cada ano.

Destacamos os anos de 2009 e 2013 com o maior número de dissertações defendidas na área da infância e raça. Em 2009 foram defendidas cinco dissertações, e em 2013, quatro. É possível perceber que não há um 
movimento crescente constante na produção acadêmica (dissertações) na temática estudada. A produção de duas dissertações por ano em 2010 e 2011 esteve no mesmo patamar das de 2007 e 2008. Houve um crescimento em 2012 (três dissertações) e 2013, apesar de decrescente, se comparado ao ano de 2009, com a maior produção acadêmica no período investigado.

Continuamos a investigação verificando em quais regiões se concentravam as pesquisas. As teses analisadas foram todas produzidas em Universidades vinculadas à região Sudeste. Não localizamos nas produções acadêmicas das regiões Norte, Nordeste, Sul e Centro-Oeste teses produzidas no mesmo período.

A maior concentração das dissertações esteve também na região Sudeste, em que foram defendidas quatorze pesquisas, seguida da região Sul - seis pesquisas, Nordeste - duas e região Norte - uma. Não encontramos nenhuma produção de dissertação ou tese na região Centro-Oeste. A análise aponta-nos que a concentração das produções sobre infância-raça está nas regiões Sudeste e Sul, o que alerta para a necessidade de Grupos de Pesquisa nas demais regiões do Brasil investirem na interface.

Com relação às Universidades onde as pesquisas foram produzidas, registramos a Universidade de São Paulo (USP), com quatro (três dissertações e uma tese defendidas), seguida pela Universidade Federal de São Carlos (UFSCAR), com três dissertações defendidas. Os demais trabalhos estão distribuídos em treze Universidades, com uma ou duas pesquisas em cada. A dispersão das produções em quinze Universidades brasileiras pode configurar um movimento positivo de inclusão da temática racial nas reflexões de grupos de pesquisa que discutem Infância e Educação Infantil. Contudo, os dados também indicam a necessidade de grupos de referência na produção acadêmica da pósgraduação em Educação no Brasil voltarem-se aos estudos relacionados à relação Educação Infantil e raça.

No que concerne à orientação, as pesquisas ficam distribuídas entre vários orientadores. A maioria deles orientou apenas uma dissertação ou tese. Somente quatro professores ${ }^{5}$ aparecem com duas pesquisas sob sua orientação.

\footnotetext{
${ }^{5}$ Eloisa Acires Rocha (UFSC); Leni Vieira Dornelles (UFRGS); Paulo Vinicius Baptista Silva (UFPR) e Petronilha Beatriz Gonçalves e Silva (UFSCAR).
} 
Destaca-se, ainda, que todas as pesquisas mencionadas nesse levantamento, tanto teses, quanto dissertações, foram produzidas por pesquisadoras do sexo feminino. Cerisara (2002) aponta a tendência de mais mulheres do que homens atuando na Educação Infantil, o que pode ser a razão desse prevalecimento se confirmar na produção de conhecimento na área.

Tal demarcação feminina na pesquisa sobre infância também se presentificou na segunda etapa do levantamento, quando buscamos identificar as comunicações orais apresentadas na ANPED no mesmo período demarcado.

\section{COMUNICAÇÕES ORAIS ANPED}

A segunda etapa constou do levantamento bibliográfico das Comunicações Orais apresentadas nas reuniões da ANPED no período de 2004 a 2013, considerando o ano de publicação das Diretrizes Curriculares Nacionais para a Educação das Relações étnico raciais e para o ensino de história e Cultura Africana e Afro brasileira - DCENERE, sendo o documento que incluiu a educação infantil como parte inerente das alterações realizadas na LDB por meio da lei $10.639 / 03$.

A pesquisa foi realizada por meio dos Anais das reuniões anuais da ANPED disponíveis no Sítio Eletrônico da referida Associação. Perpassamos as reuniões anuais de 2004 ao ano de 2013; visitamos os anais de todos os grupos de trabalho em cada uma das dez reuniões estudadas, tendo como critério de identificação os mesmos descritores utilizados na primeira etapa presentes nos títulos dos trabalhos ou títulos sugestivos que não apresentavam nenhuma destas palavras, mas abordavam temas comumente já trabalhados na discussão.

Quando identificado um título sugestivo ou qualquer uma dessas palavras no título do trabalho partíamos para a leitura do resumo e das palavras-chave no intuito de confirmar se o referido trabalho abordava a discussão das relações étnicoraciais e infância.

Identificamos 08 trabalhos que abordavam tal interface (COSTA, 2004; SILVA, 2004; ABRAMOWICZ E OLIVEIRA, 2005; JOVINO, 2008; AMARAL, 2011; ARAÚJO, 2011; PASSOS E QUEIROZ, 2012; SILVA E SOAREZ, 2013), oriundos somente de dois GTs. (07 e 21). Importante ressaltar que enquanto as discussões em torno do ensino fundamental, inclusive aquelas que contemplavam as relações 
étnico raciais estiveram presentes em quase todos os 23 GTs da ANPED, as discussões sobre a educação infantil e relações étnico raciais estiveram restritas a somente aos GTs informados. Uma vez identificados os oito textos, partíamos para a leitura dos textos completos.

Quanto às 10 (dez) reuniões anuais da ANPED, analisadas, desde 2003 até 2013, somente 06 tiveram apresentações de trabalhos sobre infância e relações étnico-raciais. Os trabalhos foram encontrados, em maior número no GT 21. O GT 07 performou 03 trabalhos no início da década estudada. Portanto, nos últimos oito anos de ANPED o GT07, onde se concentram os trabalhos relativos à educação das crianças de 0 a 05 anos em creches e pré-escolas não apresentou nenhum trabalho sobre relações étnico-raciais. (ROSA, 2016).

Após uma análise do material levantado, foi possível subdividir os 08 artigos em quatro categorias, são elas: A identidade da Criança; Crianças afrobrasileiras e literatura; A invisibilidade das crianças negras; Práticas cotidianas de educação das relações étnico-raciais.

Na categoria 1, "Infância e identidade", encontramos 02 artigos: "Bonecas: objeto de conflito identitário na arena da dominação cultural" apresentado por Costa (2004), e "As interações sociais e a formação da identidade da criança negra" apresentado por Silva (2004). Ambos foram apresentados no ano de 2004 no GT 07. Ambos discutem processos de subjetivação e construção de identidades da criança negra na educação infantil.

Na categoria 2, "Infância e literatura afro-brasileira", encontramos outros dois artigos: "Sobre maçãs e sobre mangas: notas de uma pesquisa em diálogo Com crianças afro-brasileiras e com a literatura" apresentado por Passos e Queiroz (2012) e "Pesquisas sobre literatura infanto-juvenil e relações raciais: um breve estado da arte" da autoria de Araujo (2010). Que demonstram a influência da literatura, bem como do trabalho pedagógico com a literatura na formação do sujeito leitor, bem como nos discursos racistas ou emancipatórios.

$\mathrm{Na}$ categoria 3, "A invisibilidade das crianças negras", identificamos o artigo de lone da Silva. Apresenta os resultados de uma pesquisa que buscou visibilizar a presença da criança negra no século XIX, buscando configurar a infância a partir desse recorte. Segundo a autora, a pesquisa pretendeu mostrar de que maneira as crianças negras "são dadas a ver" por meio de fotos e imagens. Conclui o trabalho apontando que ao mesmo tempo em que as práticas escravistas 
produziram exacerbadamente a imagem exótica do trabalho escravo, elas também criaram a invisibilidade das pessoas negras, em especial das crianças.

$\mathrm{Na}$ categoria 4, "Práticas cotidianas de educação das relações étnicoraciais”, identificamos 03 artigos, “A 'paparicação' na creche enquanto uma prática que inviabiliza a construção de uma educação da 'multidão' das autoras Abramowicz e Oliveira (2005), "Com a palavra as crianças: algumas reflexões sobre as Relações raciais na escola", da autoria de Amaral (2011); "Relações étnico-raciais e educação infantil: ouvindo Crianças e adultos", apresentado por Silva e Soares (2013). Nesta categoria evidencia-se a presença do preconceito e da discriminação étnico racial no cotidiano da educação infantil, embora permeado de discursos de igualdade.

\section{CONSIDERAÇÕES CONCLUSIVAS}

As publicações (artigos, teses e dissertações) destacam um cenário de desafio frente o combate ao racismo na Educação Infantil. Acreditamos que as pesquisas realizadas nas universidades viabilizam a ampliação da discussão da temática da educação das relações étnico-raciais na Educação infantil e colaboram com o delineamento do conceito de uma infância plural e diversa.

Esse entendimento corrobora com a construção do conceito de educação das relações étnico-raciais que é entendida, como um projeto de sociedade a qual não está destinada exclusivamente às crianças negras, mas para todos.

Os dados das pesquisas levantadas denunciam que as crianças negras seguem sofrendo ainda discriminações e preconceitos referentes ao seu pertencimento étnico-racial. Tal processo é prejudicial para todas as crianças contribuindo negativamente para a construção de suas identidades. As pesquisas abordaram discussões relacionadas às práticas pedagógicas, que não privilegiam a riqueza da diversidade cultural existente, configurando-se em práticas homogeneizantes. Algumas indicam mudanças a essa postura, entretanto se constituem normalmente em movimentos isolados de um professor sensibilizado com a temática. Foram poucas as pesquisas que sinalizaram um compromisso institucional de promover a educação das relações étnico-raciais ou que contemplassem essa proposta nos Projetos Políticos Pedagógicos. As pesquisas indicam a necessidade de estratégias e políticas públicas na Educação Infantil direcionadas para a educação das relações étnico-raciais, bem como de se 
efetivarem e concretizarem as que existem, entendendo que as políticas para a educação das relações étnico-raciais não dizem respeito apenas aos educadores e crianças, mas da formação social dos sujeitos, das famílias e de toda a sociedade.

A produção acadêmica estudada ressalta a necessidade de formação inicial e continuada de profissionais que atuam na Educação Infantil. Vimos, nas pesquisas, que os educadores no enfrentamento ao racismo, na tentativa de valorizar a cultura negra ou o pertencimento étnico das crianças negras, fazem-no a partir de práticas pedagógicas muitas vezes equivocadas, que tendem a reproduzir preconceitos. Para a construção de outras práticas, que não racistas, é necessário que os professores estudem e saibam o que fazer, pois ninguém pode ensinar o que não sabe.

O reduzido número de pesquisas encontradas nesse levantamento que trazem à baila as relações étnico-raciais e dão destaque à formação do professor de Educação Infantil nos leva a considerar a extrema relevância da discussão sobre as relações étnico-raciais que permeiam nossa sociedade em geral e a Educação Infantil em particular.

Rosemberg (2012, p.18) informa que: "Assistimos, apenas recentemente, a um crescente, porém ainda reduzido, número de pesquisadores (as) negros (as) e brancos (as) a se envolver com o tema da Educação Infantil, da creche, das crianças pequenas no contexto das relações raciais e de combate ao racismo". Este é outro desafio que emerge para uma educação antirracista, o aumento das pesquisas sobre infância e raça. Consideramos que o reduzido número de pesquisas que enfatizem as especificidades étnico-raciais das crianças e educadores na Educação Infantil pode colaborar para a manutenção da crença na democracia racial brasileira, reforçando que não há necessidade de um trabalho de educação das relações étnico-raciais nessa etapa.

Por outro lado, foi possível identificar também práticas voltadas à ruptura do preconceito e da discriminação étnico racial, demonstrando que quando práticas voltadas à igualdade entre negros e brancos são efetivamente desenvolvidas há mudanças afirmativas no comportamento, conceito e auto conceito de crianças brancas e negras.

A lei 10.639/03 e as DCNERER/04 impulsionaram o debate e produção acadêmica sobre relações étnico raciais também na educação infantil, porém o quantitativo de produções ainda apresenta número reduzido. Encontramos somente 
34 trabalhos ( 23 dissertações, 3 teses e 8 trabalhos na ANPED) o que ressalta a necessidade de ampliar a discussão na interface "infância, educação e relações étnico raciais", não só nas teses e dissertações acadêmicas, mas também nas comunicações orais da reunião anual da ANPED.

Percebemos no estudo o deslocamento de perspectivas críticas de exclusiva denúncia do racismo e do preconceito, para perspectivas críticas de análise da conjuntura, indicando que já existem ações de afirmação da população negra na educação infantil, porém coexistindo em paralelo à permanência de práticas conservadoras.

\section{REFERÊNCIAS}

ABRAMOWICZ, A; OLIVEIRA, F. A 'paparicação' na creche enquanto uma prática que inviabiliza a construção de uma educação da 'multidão'. In: $28^{a}$ ' Reunião Anual da ANPED, Caxambu/MG, 2005. Disponível em: http://www.28reuniao.anped.org.br/textos/gt07/gt07139int.rtf. Acesso em 18 de agosto de 2014.

\section{AMARAL, A. C. T. Com a palavra as crianças: algumas reflexões sobre as} Relações raciais na escola. In: $34^{a}$ Reunião Anual da ANPED, Caxambu/MG, 2011. Disponível em:

http://www.34reuniao.anped.org.br/images/trabalhos/GT21/GT21-1058\%20int.pdf. Acesso em 19 de outubro de 2014.

ARAÚJO, D. C. Pesquisas sobre literatura infanto-juvenil e relações raciais: Um breve estado da arte. In: 34를 Reunião Anual da ANPED, Caxambu/MG, 2011.

Disponível em: http://www.34reuniao.anped.org.br/images/trabalhos/GT21/GT2135\%20int.pdf. Acesso em 19 de outubro de 2014.

BISCHOFF, D. L. Minha cor e a cor do outro: qual é a cor dessa mistura? 2013. 115 f. Dissertação (Mestrado em Educação) - Faculdade de Educação, Universidade Federal do Rio Grande do Sul, Paraná, 2013.

BRASIL. Lei no 10.639 de 09 de janeiro de 2003 que altera a Lei no 9.394, de 20 de dezembro de 1996, que estabelece as diretrizes e bases da educação nacional, para incluir no currículo oficial da Rede de Ensino a obrigatoriedade da temática "História e cultura afro-brasileira", e dá outras providências. Diário Oficial da União, 10 jan. 2003, p. 1.

\section{Parecer CNE/CP 003/04. Diretrizes curriculares nacionais para a}

educação das relações étnico-raciais e para o ensino de história e cultura afrobrasileira e africana. Diário Oficial da União, 10 mar. 2004. 
CABRAL, M. A. Identidade étnico-racial em contexto lúdico: um jogo de cartas marcadas? 2007. 118 f. Dissertação (Mestrado em Educação) - Faculdade de Educação, Universidade Federal do Ceará, Fortaleza, 2007.

CARVALHO, T. R. de. Políticas de promoção da igualdade racial na rede municipal de educação infantil de Florianópolis. 2013. 267 f. Dissertação (Mestrado em Educação) - Faculdade de Educação, Universidade Federal do Paraná, Curitiba, 2013.

CERISARA. Ana B. Professoras de educação infantil: entre o feminino e o profissional. 2 ed. São Paulo: Cortez, 2002. (Questões da Nossa Época, v. 98).

COSTA, M. F. V. Bonecas: objeto de conflito identitário na arena da dominação cultural. In: 27를 Reunião Anual da ANPED, Caxambu/MG, 2004. Disponível em: http://www.27reuniao.anped.org.br/gt07/t074.pdf. Acesso em 17 de agosto de 2014.

COSTA, R. de A. A criança negra: as representações sociais de professores de educação infantil. 2013. 194 f. Dissertação (Mestrado em Educação) - Faculdade de Educação, Universidade do Estado do Pará, Belém, 2013.

DIAS, Lucimar Rosa. No fio do horizonte: educadoras da primeira infância e o combate ao racismo. São Paulo: Tese (Doutorado) - Faculdade de Educação da Universidade de São Paulo, 2007.

GAUDIO, E. S. Relações sociais na educação infantil: dimensões étnico-raciais, corporais e de gênero. 2013. 242 f. Dissertação (Mestrado em Educação) -

Faculdade de Educação, Universidade Federal de Santa Catarina, Florianópolis, 2013.

GOMES, N. L. Movimento negro e educação: ressignificando e politizando a raça. Revista Educação e Sociedade, vol. 33, num. 120, julho - setembro, 2012, p. 727744. Disponível em: http://www.cedes.unicamp.br. Acesso em 15 de maio de 2015.

JOVINO, I. S. Entre o sentimento da infância e a invisibilidade das crianças negras: ambigüidade no século XIX. In: $31^{a}$ Reunião Anual da ANPED, Caxambu/MG, 2008. Disponível em:

http://www.31 reuniao.anped.org.br/1trabalho/GT21-4281--Int.pdf. Acesso em 20 de outubro de 2014.

MONTEIRO, Nelma Gomes. Afirmar as diferenças etnicorraciais como processo de enunciação para o enfrentamento do racismo na educação infantil. Espírito Santo: Tese (Doutorado) - Faculdade de Educação da Universidade de Espírito Santo, 2010.

MOTTA, S. L. Diversidade e diferença: um estudo na creche Fiocruz. 2010. $151 \mathrm{f}$. Dissertação (Mestrado em Educação) - Faculdade de Educação, Universidade do Estado do Rio de Janeiro, Rio de Janeiro, 2010. 
NUNES, M. D. F. Histórias de ébano: professoras negras de educação infantil da cidade de São Paulo. 2012. 308 f. Dissertação (Mestrado em Educação) - Faculdade de Educação, Universidade de São Paulo, São Paulo, 2012.

OLIVEIRA, Fabiana de. Um estudo sobre a creche: o que as práticas educativas produzem e revelam sobre a questão racial. Dissertação (mestrado). São Paulo: Faculdade de Educação da Universidade Federal de São Carlos - UFSCAR, 2004.

OLIVEIRA, W. T. F. Trajetórias de mulheres negras na educação de crianças pequenas no distrito do Jaraguá, em São Paulo: processos diferenciados de formação e de introdução no mercado de trabalho. 2006. 149 f. Dissertação (Mestrado). Pontifícia Universidade Católica de São Paulo, São Paulo, 2006.

OLIVEIRA, A. dos S. Mulheres negras e educadoras: de amas de leite a professoras. Um estudo sobre a construção de identidades de mulheres negras na cidade de São Paulo. 2009. 258 f. Dissertação (Mestrado em Educação) - Faculdade de Educação, Universidade de São Paulo, São Paulo, 2009.

OLIVEIRA, V. C. de S. Educação das relações étnico-raciais e estratégias ideológicas no acervo do PNBE 2008 para Educação Infantil. 2011. 190p. Dissertação (Mestrado em Educação) - Faculdade de Educação, Universidade Federal do Paraná, 2011.

OLIVEIRA, S. M. de. A formação de atitudes racistas em uma unidade de educação infantil em Belo Horizonte: o que as rotinas e as interações entre as crianças nos revelam. 2012. 157 f. Dissertação (Mestrado em Educação) Faculdade de Educação, Pontifícia Universidade Católica de Minas Gerais, Belo Horizonte, 2012.

PASSOS, M. C. P.; QUEIROZ, C. A. Sobre maçãs e sobre mangas: notas de uma pesquisa em diálogo Com crianças afro-brasileiras e com a literatura. In: $35^{\mathrm{a}}$ Reunião Anual da ANPED, Caxambu/MG, 2012. Disponível em: http://www.35reuniao.anped.org.br/images/stories/trabalhos/GT21\%20Trabalhos/GT 21-1841_int.pdf. Acesso em 19 de novembro de 2014.

PEREIRA, Erika Jennifer Honorio. "Tia, existe flor preta?" Educar para as relações étnico-raciais. Dissertação de mestrado. Programa de Pós-Graduação em Educação. Universidade Estadual do Rio de Janeiro. Rio de Janeiro, 2015.

QUEIROZ, C. A. "De uma chuva de manga ao funk de Lelê": imagens da afrodiáspora em uma escola de Acari. 2011. 148 f. Dissertação (Mestrado em Educação) - Faculdade de Educação, Universidade do Estado do Rio de Janeiro, 2011.

ROCHA, L. J. P. Educação infantil pré-escolar: um espaço/tempo para práticas antirracistas. 2008. 114 f. Dissertação (Mestrado em Educação) - Faculdade de Educação, Universidade Federal do Estado do Rio de Janeiro, Rio de Janeiro, 2008.

ROSA, A. S. Creche e educação das relações étnico raciais: uma leitura a partir do espaço. Projeto de qualificação de tese de doutorado. Programa de Pós- 
graduação em Educação. Universidade do Estado do Rio de Janeiro. Rio de Janeiro, 2016.

ROSEMBERG, F. Aspectos conceituais e jurídicos da educação para a igualdade racial na educação infantil. In: BENTO, M. A. S. (ORG.). Educação infantil, igualdade racial e diversidade: aspectos políticos, jurídicos e conceituais. São Paulo: CEERT, 2012. p. 11-46.

SANTOS, A. Identidade negra e brincadeira de faz-de-conta: entremeios. Dissertação de mestrado. Faculdade de Educação. Universidade Federal de Juiz de Fora. Juiz de Fora, 2005.

SANTOS, M. A. dos. Educação da primeira infância negra em Salvador: um olhar sobre as políticas educacionais. 2008. 166 f. Dissertação (Mestrado em Educação) Faculdade de Educação, Universidade Federal da Bahia, Salvador, 2008.

SARAIVA, C. F. Educação infantil na perspectiva das relações étnico-raciais: relato de duas experiências de formação continuada de professores no município de Santo André. 2009. 353 f. Dissertação (Mestrado em Educação) - Faculdade de Educação, Pontifícia Universidade Católica de São Paulo, São Paulo, 2009.

SILVA, C. I. O acesso das crianças negras à educação infantil: um estudo de caso em Florianópolis. 2007. 95 f. Dissertação (Mestrado em Educação) - Faculdade de Educação, Universidade Federal de Santa Catarina, Florianópolis, 2007.

SILVA, S. A.; SOARES, L. N. Relações étnico-raciais e educação infantil: ouvindo Crianças e adultos. In: 36 $6^{\underline{a}}$ Reunião Anual da ANPED, Caxambu/MG, 2013. Disponível em:

http://www.36reuniao.anped.org.br/pdfs_trabalhos_aprovados/gt21_trabalhos_pdfs/g t21_3271_texto.pdf. Acesso em 19 de novembro de 2014.

SILVA, V. L. N. As interações sociais e a formação a identidade da criança negra. In: 27aㅡ Reunião Anual da ANPED, Caxambu/MG, 2004. Disponível em: http://www.27reuniao.anped.org.br/gt07/t079.pdf. Acesso em 17 de agosto de 2014.

SOUZA, Y. C. de. Atravessando a Linha Vermelha: Programa "Nova Baixada" de educação infantil - discutindo a diversidade étnico-racial e cultural na formação docente. 2009. 121 f. Dissertação (Mestrado em Educação) - Faculdade de Educação da Baixada Fluminense, Universidade do Estado do Rio de Janeiro, Rio de Janeiro, 2009.

SOUZA, F. M. de. Revirando malas: entre histórias de bonecas e crianças. 2009. 134 f. Dissertação (Mestrado em Educação) - Faculdade de Educação, Universidade Federal do Rio Grande do Sul, Porto Alegre, 2009.

SOUZA, E. de L. Percepções de infância de crianças negras por professoras de Educação Infantil. 2012. 123p. Dissertação (Mestrado em Educação) - Faculdade de Educação, Universidade Federal de São Carlos, São Carlos, 2012. 
TELES, C. de P. Representações sociais sobre as crianças negras na educação infantil: mudanças e permanências a partir da prática pedagógica de uma professora. 2010. 171 f. Dissertação (Mestrado em Educação) - Faculdade de Educação, Universidade Federal de São Paulo, São Paulo, 2010.

TRINIDAD, Cristina Teodoro. Identificação étnico-racial na voz de crianças em espaços educação infantil. Tese (Doutorado em Educação) - Pontifícia Universidade Católica de São Paulo, 2011.

VASCONCELLOS, V. M. R.; SARMENTO, M. J. (orgs.). Infância (in) visível. Araraquara: Junqueira \& Marin, 2007. 